\title{
HORIZONTES DE PLAUSIBILIDADE SOB A CRÍTICA DA FILOSOFIA: ENTRE LUZES, HORRORES E VÍTIMAS
}

\author{
HORIZONS OF PLAUSIBILITY UNDER THE CRITICAL PHILOSOPHY: BETWEEN LIGHTS, HORRORS AND VICTIMS
}

HORIZONTES DE PLAUSIBILIDAD BAJO LA CRÍTICA DE LA FILOSOFÍA: ENTRE LUZES, HORRORES Y VÍCTIMAS

\author{
COELHO, Allan da Silva ${ }^{1}$
}

\begin{abstract}
RESUMO
A Modernidade e o capitalismo consolidam um marco categorial que referencia a normalidade da vida, o modo de ser humano válido e seus horizontes de compreensão. Esse processo direciona os símbolos que permeiam o conhecimento, com significados tacitamente aceitos, condicionando o pensar, mas permanecendo impensado. O neoliberalismo radicaliza tal perspectiva colocando a vida humana sob ameaça. Os estudos do "capitalismo como religião", em especial como matizado pela Escola do DEI, pode colaborar com esta temática já esboçada na Educação. Tendo como referência a vítima real e concreta, investigamos que tipo de contribuições esse setor pode oferecer à renovação da Filosofia da Educação tornando os critérios de plausibilidade um problema ético-educacional no enfrentamento da modernidade capitalista. A investigação teórico-bibliográfica, referenciada pela dialética compreensiva, permite caracterizar e inventariar possibilidades desta articulação categorial.
\end{abstract}

Palavras-chave: Horizonte de plausibilidade. Capitalismo como religião. Escola do DEI. Vítimas. Perspectiva descolonial.

\section{ABSTRACT}

Modernity and capitalism consolidate a categorial framework that refers to the normality of life, the valid human way of being and its horizons of understanding. This process directs the symbols that permeate knowledge, with tacitly accepted meanings, conditioning thinking but remaining unthought. Neoliberalism radicalizes such a perspective by placing human life under threat. The "capitalism as religion" studies, especially as qualified by the DEI School, can collaborate with this theme already outlined in Education. Taking as reference the real and concrete victim, we investigated what type of contributions this sector can offer to the renewal of the Philosophy of Education, making plausibility criteria an ethical-educational problem in the face of capitalist modernity. The theoretical-bibliographic research, referenced by the comprehensive dialectic, allows to characterize and inventories possibilities of this categorical articulation

Keywords: Horizon of plausibility. Capitalism as religion. DEI School. Victims. Decolonial perspective.

\section{RESUMEN}

La modernidad y el capitalismo consolidan un marco categorial que referencia a la normalidad de la vida, del modo de ser humano válido y de sus horizontes de comprensión. Este proceso dirige los símbolos que permean el conocimiento, con significados tácitamente aceptados, condicionando el pensar, pero permaneciendo impensado. El neoliberalismo radicaliza tal perspectiva poniendo la vida humana bajo amenaza. Los estudios del "capitalismo como religión", en especial como matizado por la Escuela del DEI, pueden colaborar con esta temática ya esbozada en la Educación. Refiriéndose a las víctimas reales y concretos, investigamos qué tipo de contribuciones este sector puede ofrecer la renovación de la Filosofía de la Educación haciendo que los criterios de plausibilidad problema ético-educativa frente la modernidad capitalista. La investigación teóricobibliográfica, referenciada por la dialéctica comprensiva, permite caracterizar e inventariar posibilidades de esta articulación categorial.

Palabras clave: Horizonte de plausibilidade. Capitalismo como religión. Escuela del DEI. Víctimas. Perspectiva descolonial.

\footnotetext{
1 Universidade Metodista de Piracicaba - UNIMEP - Piracicaba - São Paulo - Brasil
} 


\section{INTRODUÇÃO}

Walter Benjamin afirmou que o processo de colonização das Américas gera uma nova "Geistesverfassung", isto é, uma configuração espiritual, outra mentalidade, que não poderia ser representada sem horror (BENJAMIN, 2013). Quando Benjamin associa o horror como qualidade desta nova configuração, propõe um julgamento ético do qual não se dissocia na sua interpretação. Michael Löwy (2005), discutindo esta passagem, afirma que a realidade atual da globalização capitalista neoliberal também pode (e deve) ser observada com a mesma percepção de horror. Essa relação promove uma boa síntese de nossa abordagem: a colonização das Américas inicia um processo de transformações que leva, ao mesmo tempo, ao que chamamos de Modernidade e de sistema capitalista, configurando uma outra mentalidade em que o horror e o injusto passam por razoáveis. $O$ desafio principal está no fato de que, apesar da atrocidade desta reconfiguração do mundo, a infâmia e a crueldade estão de tal forma naturalizados e normalizados que compreender o horror e realizar sua crítica somente é possível desvendando sua lógica de funcionamento.

Segundo Franz Hinkelammert (2008), entender a estratégia da globalização neoliberal supõe reconstituir o percurso pelo qual entramos na Modernidade, em busca do "fio de Ariadne" que permita combater seus efeitos. Pode-se dizer que valem para a ideia de globalização as características da "jaula de aço" de Weber, isto é, aceita-se seu processo como um "vasto e sistêmico maquinário impessoal, que existe e se desenvolve de modo independente das decisões humanas, quer dizer, de um certo modo natural e, nesse sentido, inevitável, e que abarcaria e explicaria todas as atuais ações humanas" (QUIJANO, 2002, p.06). No neoliberal, a estratégia capitalista amplia a superexploração e acirra a reversão de direitos, através do desmonte de políticas públicas de cidadania e na aplicação das medidas de "Austeridade". A mesma lógica, no conjunto, aplica-se à educação, com a redução de seu caráter público e de cidadania, no contingenciamento de recursos e pressão pela privatização desde sua concepção até a execução, pelas mais diversas maneiras que proporcionem lucro. Anibal Quijano alerta que a exploração econômica supõe sempre algum tipo de dominação social. A força e a violência são aspectos da dominação, mas não são exercidas de forma explícita continuamente. Ele afirma que:

\footnotetext{
Todo o tempo de derrota dos explorados e dominados permite aos que controlam o poder realizar mudanças profundas nas relações sociais de poder e muitas delas profundas e irreversíveis. (...) Em outras palavras, a exploração tornou-se mais forte e a dominação mais direta (QUIJANO, 2002, p. 24).
}

As condições históricas em que se compreende esse processo é a imposição do chamado "pensamento único" desde o fim da experiência do socialismo real (1989 a queda do Muro de Berlim, em 1991 o fim da URSS) e a ação das organizações econômicas como a Organização Mundial do Comércio, o Banco Mundial ou o Fundo Monetário Internacional. Neste contexto, a celebração dos 500 anos da conquista da América, em 1992, provocou a reflexão se haveria motivo a comemorar.

$\mathrm{O}$ ano de 1492, de forma emblemática, serve-nos como ponto de referência. Enrique Dussel (2000) também defende que há uma relação direta entre a nova configuração espiritual que surge na 
colonização, apontada por Walter Benjamin, com modus operandi do sistema capitalista globalizado hoje. Uma modificação articulada na forma de pensar e agir, que reconfigura a compreensão do mundo e do ser humano. Gesta-se uma nova mentalidade que supõe uma nova compreensão ética, política e antropológica, a partir da qual se formulam os projetos de formação humana. Na ocasião dos 500 anos de descobrimento - e/ou de invasão - Dussel foi convidado à Escola de Frankfurt e ministrou uma série de palestras em que organiza um conjunto de intuições com as quais diversos autores latinoamericanos vem trabalhando (DUSSEL, 1993). Tais reflexões não são exatamente novas e recebem influência tanto da própria Escola de Frankfurt, como de marxismos heterodoxos, mas são fecundados pelas lutas sociais e políticas vividas desde os anos 1950 na América Latina. É neste mesmo momento que se desenvolve a articulação do grupo "Modernidade/Colonialidade" que também articula sua crítica na convergência do processo de colonização da América Latina e a consolidação do capitalismo, mas associados à hierarquização de raças, como alicerces da Modernidade. Enrique Dussel é um dos participantes desta articulação, bem como foi um ativo membro dos seminários de pesquisadores do DEI - Departamento Ecuménico de Investigaciones.

Delimitando a argumentação, nos orientamos pelas considerações de Dussel pelo fato de sua presença em ambos os coletivos de intelectuais que nos fornecem instrumentais analíticos importantes para nossa questão. Ambos coletivos possuem diversidade teórica e pluralidade de ênfases distintas. Nosso recorte propõe destacar a tendência que aproxima dialeticamente a exploração econômica do modo de produção capitalista com as formas de dominação da subjetividade e da cultura como um sistema social. A abordagem privilegia o trabalho metodológico desenvolvido junto ao DEI, que constitui o campo latino-americano da crítica ao "capitalismo como religião", mas em diálogo com a perspectiva descolonial e a metodologia dialético-compreensiva.

Aqui, questionamos que tipo de contribuições esse setor do pensamento crítico latino americano que se articulou em torno à Escola do DEI pode oferecer à renovação da Filosofia da Educação a partir da crítica dos horizontes de plausibilidade da modernidade capitalista? Trabalhamos com a hipótese de que diversas tarefas podem ser pensadas estimulando a revisar as abordagens da Filosofia da Educação. Através da investigação teórico-bibliográfica, caracterizamos a Escola do DEI no contexto do pensamento crítico latino americano, para que se compreenda as premissas que fundamentam nossa abordagem. Em seguida, apresentamos o tema central desta investigação que é a discussão sobre o horizonte de compreensão da vida na Modernidade articulado à disputa de significados e apostas fundamentais, indicando um caminho a ser percorrido.

\section{O DEI E O PENSAMENTO CRÍTICO LATINO-AMERICANO}

A expressão "Escola do DEl" é utilizada para referir-se ao setor do cristianismo de libertação² que desenvolve um pensamento crítico articulando as ciências sociais e a teologia, em especial, por

\footnotetext{
${ }^{2}$ Cristianismo de libertação é o movimento social que constitui e do qual se origina a Teologia da Libertação. 0 conceito é mais amplo, pois supõe a ação social e, por vezes, revolucionária, de cristãos engajados que não eram
} 
compreender de forma estruturante as relações entre teologia e marxismo ${ }^{3}$. Recebe este nome em relação ao Departamento Ecumênico de Investigações - DEI, centro de articulação e estudos resultado dos esforços de Hugo Assmann, Pablo Richard e Franz Hinkelammert (que incorpora também Enrique Dussel), entre outros/as (SUNG, 2008). Gestado no Chile, na confluência entre exilados e militantes na experiência dos governos Frei e Allende, bem como na dura repressão militar e política de Pinochet. $O$ DEI instalou-se em San José, na Costa Rica, nos anos 1970. A expressão remete mais ao grupo que se articula para uma perspectiva metodológica, do que ao instituto estabelecido no bairro costarriquenho de Sabanilla4 . A principal característica do método desenvolvido é conceber a crítica do sistema capitalista a partir da integração produção material e do espírito, isto é, entende a produção simbólica espiritual como profundamente articulada a produção econômica-material. A produção teológica 5 é compreendida como fundamental na crítica da racionalidade econômica e sua ideologia sacrificial: na crítica do capitalismo como religião idolátrica, a teoria do fetiche de Marx foi estudada restituindo seus aspectos teológicos, associada ao conceito de idolatria. A dimensão mítico-teológica é compreendida em dialética com as dimensões econômicas e epistêmicas. Partindo de um problema concreto - a legitimação da morte das pessoas humanas em nome do bem do sistema - e comprometidos com uma tarefa histórica - colaborar na revolução latino-americana, a abordagem interdisciplinar discutiu principalmente a apropriação e inversão dos mitos cristãos pelo capitalismo, a relação entre razão utópica e sacrificialismo, a afirmação do sujeito humano frente a absolutização das instituições e/ou lei. Enrique Dussel incorporou a relação entre a idolatria e teoria do fetiche ainda nos anos 1970 e assume a crítica à razão utópica nos anos 1990.

$\mathrm{Na}$ proposta de uso da perspectiva descolonial ${ }^{6}$, entendemos que as diferenças entre os estudos subalternos, as teorias pós-coloniais e descoloniais são importantes e não as desconsideramos. Lauri Wirth afirma que estas perspectivas representam "um esforço teórico múltiplo, historicamente situado e de caráter aberto, não só no sentido de inacabado, mas principalmente por

nem consagrados ou membros do clero, mas tiveram atuação significativa desde sua origem até os dias de hoje. (cf. LÖWY, 2016).

${ }^{3}$ Tal perspectiva teórica é uma das possíveis concretizações históricas da Tese I de Walter Benjamin em "Sobre o Conceito de História", com a clássica alegoria do anão e do boneco autômato. Estudamos as convergências entre Benjamin e este setor do pensamento crítico latino-americano em COELHO, 2014.

${ }^{4}$ Não há consenso em utilizar as expressões Escola do DEI ou Escola DEI (sua variação). Faz sentido, pois tal articulação inicia-se antes do DEI. Mas a contestação deve-se mais ao fato de que o instituto que hoje existe não tem mais relação com seus fundadores e os mesmos não se reconhecem no projeto em vigor. Richard e Hinkelammert foram desligados de suas funções no DEI.

${ }^{5}$ Esta produção é uma das expressões da Teologia da Libertação Latino-Americana (TdL). Há diversas TdLs, sendo a ênfase fundamental deste setor a dialética teologia-economia incorporando estruturalmente as categorias marxistas. Outros propõem utilizar o marxismo apenas na reflexão sobre a sociedade e, ainda, há aqueles que dispensam tal instrumental analítico. Não significa dizer que os teólogos e teólogas podem ser rigorosamente classificados, uma vez que em cada época de sua vida e obra podem receber maior ou menor influência de métodos diferentes.

6 A denominação também não é consenso. Pós-colonial enfatiza a situação que se configura depois da colonização política, cujo fim não necessariamente permitiu o fim de uma relação colonial ou de colonialidade. No entanto, os esforços deste setor que se chamou de pós-colonial já receberam outras denominações, como transmoderno ou mesmo pós-moderno. Dussel, nos anos 1970, usou o "pós-moderno" em uma perspectiva muito diferente daquela consagrada nos anos 1980 por Lyotard, por exemplo. Boaventura reivindicou-se "pósmoderno de oposição", antes de optar pelo termo pós-colonial. 
referenciar-se a formas múltiplas de conhecimentos e saberes" (WIRTH, 2013, p.129). Ramon Grosfoguel destaca três de suas características: o cânone de pensamento mais amplo que o ocidental (mesmo de esquerda), um diálogo entre subalternizados ("sul-sul") e a discussão crítica entre projetos alternativos concretos (GROSFOGUEL, 2008). Bill Ashcroft propõe uma definição ampla para a abordagem pós-colonial incluindo pensadores e ativistas que, desde a condição de subalternidade, enfatizam a experiência do colonialismo como formador da subjetividade e considerem as diferenças em relação ao poder imperial. Além disso, a exigência fundamental é assumir um posicionamento (ASHCROFT et ali., 1995). Compartilhar desta exigência indica que, mais importante que a pertença a um coletivo que compartilha perspectivas teóricas múltiplas, é o uso do instrumento categorial do giro descolonizador na responsabilidade política frente a globalização neoliberal.

Desse modo, se a tentativa de classificação é válida e ajuda a compreender nuances, ela não é estanque e não abarca toda a rica pluralidade em suas descrições. Se parece certo que os estudos pós-coloniais teriam maior ênfase nas relações culturais e maior dependência das teorias estruturalistas, nem todos aqueles que utilizam a categoria deixam de lado a articulação entre o imaginário e o simbólico com as questões econômicas. Da mesma forma que, se muito marxismos são deterministas e entendem as relações econômicas como determinantes do mundo simbólico-espiritual, há diversos marxismos que reivindicam outra concepção de dialética que permite entender a cultura entrelaçada com os processos de produção. Parece que a Escola do DEI contém participantes na encruzilhada destas potencialidades e limites. Mais do que diferenciar as perspectivas críticas à colonialidade $^{7}$, é possível reivindicar as contribuições que variadas abordagens podem oferecer. É preciso evitar a reprodução de certa lógica da Modernidade de clareza e distinção que visa criar hierarquias e ranqueamentos. A questão fundamental deve permitir entender a serviço de quem estão certas teorias e quais de seus aspectos colaboram com a transformação da realidade de exploração e dominação. Neste sentido, é uma opção possível, entre outras válidas, a grafia do termo em português como "descolonial", com o prefixo "des", em seu significado de oposição e negação ao conceito. Descolonial expressa justamente a recusa de um neologismo anglicista e a indicação de uma estratégia teórica e política necessária: entender o processo pelo qual se forma nossa "configuração espiritual" para encontrar o fio de Ariadne que permite sua negação. Aponta como um projeto utópico necessário de novas estruturas e instrumental radicalmente crítico, sem ilusão de apagar os rastros da colonialidade $^{8}$. Não é, justamente, uma perspectiva de desconstrução, mas de ruptura dialética, subsumida ou antropofágica, como bem ilustra Gloria Anzaldúa (2005).

\footnotetext{
${ }^{7}$ Colonialidade entendida como "um padrão de poder que opera através da naturalização de hierarquias territoriais, raciais, culturais, libidinais e epistêmicas que possibilitam a reprodução de relações de dominação que garantem a exploração pelo capital de uns seres humanos por outros a escala planetária" (CASTRO-GÓMES e RESTREPO, 2008, p.24).

${ }^{8}$ Aqui tomamos a liberdade de dialogar com o argumento de Catherine Walsh (2009), utilizado justamente em favor do uso do termo "decolonial". Seu argumento poderia ser utilizado de outra forma. Porém, não estamos convencidos de que o caráter anglicista seja eliminado do termo decolonial.
} 
Por isso, mais do que a filiação a uma perspectiva teórica, proponho entender as críticas da Escola do DEl fecundadas pela força do conceito de "giro descolonial", como definido por Nelson Maldonado-Torres:

\begin{abstract}
Em primeiro lugar, uma mudança de perspectiva e atitude que se encontra nas práticas e formas de conhecimento de sujeitos colonizados, desde os inícios mesmos da colonização, e, em segundo lugar, um projeto de transformação sistemática e global dos pressupostos e implicações da modernidade, assumido por uma variedade de sujeitos em diálogo (MALDONADO-TORRES, 2007, p.160).
\end{abstract}

Como mudança de atitude do sujeito e como projeto de transformação, o descolonial indica a tentativa de uma forma diversa de pensar e constituir o saber como forma de superar os limites da dominação moderna. As mudanças de temas, opções de abordagem e perspectivas de análises estão sendo chamadas de "giros", mas, em alguns casos, cumprem sua vocação a ser verdadeiras rupturas. Acertadamente, Maldonado-Torres alerta que o giro descolonial e a ideia de descolonização devem ser tão antigas como a colonização moderna, isto é, existe resposta e recusa à ação colonial desde que os conquistadores colocaram seu projeto em ação:

\begin{abstract}
(...) Encontram suas raízes na resposta visceral dos sujeitos conquistados ante a violência extrema da conquista, que invalida os conhecimentos, formas de ser, e até mesmo a humanidade dos conquistados. Os princípios do giro de-colonial e a ideia de de-colonização se fundam sobre o "grito" de espanto do colonizado ante a transformação da guerra e a morte em elementos ordinários de seu mundo de vida, que se transforma, em parte, em mundo da morte, ou em mundo da vida apesar da morte (MALDONADOTORRES, 2007, p.159).
\end{abstract}

Esta passagem evidencia temas que consideramos relacionados diretamente, como o modo de conhecer e o modo de ser-viver e encarar a vida. A resistência que fundamenta a crítica advém, primeiro, da experiência histórica de negação de sua humanidade (como em Paulo Freire) e do grito em que se sujeitiza9 ${ }^{9}$ quem deseja "ser mais". Introduz, neste parágrafo, o tema do sujeito crítico que na prática é a vítima do projeto colonial e da modernidade. Este é um tema central na Escola do DEl. Dussel afirma que o mais importante do "giro descolonizador" está em estabelecer seu locus enuntiationis, como local epistemológico "das vítimas, do Sul do Planeta, os oprimidos, os excluídos, os novos movimentos populares, os povos ancestrais (...), nas redes mundiais altermundistas" (DUSSEL, 2014, p.556), como o onde se faz a crítica a todo o conjunto sistemático de categorias da Filosofia. Mais adiante retornaremos ao tema central da vítima.

\footnotetext{
${ }^{9}$ Franz Hinkelammert estuda o papel do grito do sujeito que nega a legitimidade da ordem que o oprime, denunciando-a como injusta, no conceito de sujeito rebelde. Veja: HINKELAMMERT, 1998 ou 2002. Curiosamente, Hinkelammert debate estas categorias com o Instituto Pensar da Universidad Javeriana de Colombia, um dos pólos de articulação do grupo Modernidade/Colonialidade.
} 


\section{HORIZONTE DE COMPREENSÃO DA MODERNIDADE}

Para entendermos a questão, propomos acompanhar Istváz Mészáros, marxista que discutindo a educação permite exemplificar o tema apresentado. Mészáros (2005) afirma que os seres humanos vivem sob condições de "desumanizante alienação" e de uma "subversão fetichista do real estado de coisas dentro da consciência" (também caracterizada pela reificação). Alienação, fetichismo e reificação caracterizam funções sociais que são exercidas pela lógica do capital como único modo de assegurar sua ampla reprodução. A transformação dessas condições exige intervenção consciente a partir da existência individual e coletiva, pois "segundo Marx, os seres humanos devem mudar completamente as condições da sua existência (...), toda a sua maneira de ser" (MÉSZÁROS, 2005, p.59).

O capitalismo não se limita a um modo de produção, mas constitui um sistema social e uma maneira de ser. As relações econômicas e sociais capitalistas constituem uma forma específica de viver que conformariam o ser humano não apenas pela prática cotidiana, mas também pelo processo formal de aprendizado educacional. A educação tem importância estratégica na internalização de uma concepção hegemônica, servindo, em geral,

\footnotetext{
ao propósito de não só fornecer os conhecimentos e o pessoal necessário à máquina produtiva em expansão do sistema do capital, como também gerar e transmitir um quadro de valores que legitima os interesses dominantes, como se não pudesse haver nenhuma alternativa à gestão da sociedade. (MÉSZÁROS, 2005, p.35).
}

O processo educativo está em sintonia com o sistema social vigente não apenas por preparar para o trabalho humano referenciado na estratégia capitalista de produção, mas também por conformar uma visão de mundo específica de legitimação que está associado ao não menos importante aspecto de ocultar e deslegitimar qualquer tipo de alternativa (pensamento único). No entanto, a educação não cumpre apenas o papel de reproduzir e conformar as bases materiais e ideológicas do sistema (como em certo marxismo ortodoxo), mas também nas propostas de ruptura com a internalização predominante. Para ele,

\footnotetext{
Também essa 'contrainternalização' (ou contraconsciência) exige a antecipação de uma visão geral, concreta e abrangente, de uma forma radicalmente diferente de gerir as funções globais de decisão da sociedade, que vai muito além da expropriação, há muito estabelecida, do poder de tomar todas as decisões fundamentais, assim como das suas imposições sem cerimônias aos indivíduos, por meio de políticas como uma forma de alienação por excelência na ordem existente. (MÉSZÁROS, 2005, p.61).
}

Os elementos do raciocínio de Mészáros demonstram aspectos centrais. A compreensão de que a produção se articula a um sistema social, que indica uma maneira de ser, isto é, aponta aspectos característicos para a normalidade da vida humana. Tais características não são naturais, biológicas ou inatas (por mais que cada época as proponha como tal), mas desenvolvidas pela mediação da vida, na cultura. São "configurações espirituais", que possuem em seus pressupostos conceitos sobre a 
finalidade da vida (teleologia), sobre o que é o ser humano (antropologia), o que é o agir certo (ética) e de como deve ser melhor organizada a vida em comum (política).

O conjunto dos pressupostos constituem a base do ethos (sentido weberiano) de cada época. O processo educacional tem papel fundamental no aprendizado do modo de ser, mas também na superação/constituição de modos alternativos. Para tanto, Mészáros aponta a necessidade da "antecipação de uma visão geral, concreta e abrangente", que entendemos em relação a um horizonte de compreensão, que sirva de parâmetro de comparação e permita a elaboração de estratégias apropriadas e adequadas para mudar as condições objetivas de reprodução e para a mudança consciente das pessoas na gestação de uma ordem social diferente. Por isto, para Mészáros, não surpreende que "na concepção marxista a 'efetiva transcendência da autoalienação do trabalho' seja caracterizada como uma tarefa inevitavelmente educacional" (MÉSZÁROS, 2005, p.65).

A educação, em seu sentido mais amplo, pode fornecer uma orientação concreta para a transformação social emancipadora radical requerida. Para tanto, deve estar articulada adequadamente e redefinida dialeticamente, pois uma educação alternativa (para ele, uma "concepção socialista da educação") "é qualitativamente diferente mesmo dos ideais educacionais mais nobres da burguesia ilustrada, formulados na fase ascendente do desenvolvimento capitalista" (MÉSZÁROS, 2005, p.84). Mesmo que o marxismo se considere um legítimo herdeiro do lluminismo, haveria uma diferença que não é superficial, mas corresponde à visão de mundo e as decorrentes concepções de ser humano. Estes elementos precisam ser melhor estudados para evitar que propostas educacionais alternativas correspondam, em seu fundamento, ao ideal ilustrado burguês.

Nesse ponto, a crítica de Dussel ao paradigma da Modernidade contribui para a pensar a questão com outros elementos. O lluminismo ${ }^{10}$ autocompreende a Modernidade com um projeto civilizacional de emancipação, de saída da imaturidade pela razão no esclarecimento. Pela simbologia da luz, que representando a razão expressa desde uma forma de pensar racional e autônoma do indivíduo, como também o desenvolvimento técnico e uma compreensão de progresso individual, científico e histórico como acumulação ilimitada e evolução como constante aperfeiçoamento. Esta compreensão encontraria sua verificabilidade histórica na Europa, como Paris, a cidade luz, expressão do desenvolvimento racional da cidade e da cultura. Essa luz ilumina a saída da condição de imaturidade e selvageria em que boa parte da humanidade se encontra, visando alcançar a "secreta finalidade da ordem do mundo" (disse Kant). Supõe um esforço formativo-educacional, para que o homem realiza a própria humanidade (KANT, 2011).

Desse modo, encontramos na concepção educacional de Kant, por exemplo, a educação como um processo de saída da menoridade em busca da autoemancipação pela razão. O ser humano é culpado de sua menoridade, abdicando da moral e do necessário domínio sobre a propensão ao mal, por subserviência, preguiça e covardia. É preciso coragem e decisão para superar o atraso e a imaturidade, que o mantém na condição de bárbaro. O humano é incapaz de se servir de seu próprio

\footnotetext{
${ }^{10}$ É interessante a proposta de deslocamento e modificação do uso da razão moderna no racionalismo, depois no lluminismo, até a radicalização epistêmica do Positivismo. A título de ilustração, vamos nos limitar neste texto ao lluminismo.
} 
entendimento sem a orientação de outro. Por isso, a educação supõe domar a selvageria que prejudica o caráter humano, transmitir a civilidade e cuidar do uso da razão, tendo como perspectiva "um estado melhor, possível no futuro, isto é, segundo a ideia de humanidade e de sua inteira destinação" (KANT, 2011, p.22). ${ }^{11}$

A civilização moderna, segundo Dussel (2005), se descreve como mais desenvolvida e superior, sendo que tal superioridade impõe a obrigação moral de desenvolver os mais primitivos e bárbaros, para que atinjam o padrão racional que a civilização europeia conquistou. Entretanto, os bárbaros opõem-se ao processo civilizador, o que impõe a violência para domar a selvageria. Esta dominação produz vítimas, mas é inevitável, como sacrifício necessário, se desejamos o bem futuro de toda a humanidade. A culpa da violência é o bárbaro, que em sua imaturidade resiste ao uso pleno da razão.

Na realidade, visão iluminista, derivada do "ego cogito" que define o humano pelo uso de certa razão, reflete um marco categorial que oculta sua própria irracionalidade. A luz desta razão tem em suas sobras os rastros da conquista colonial, que de forma irracional classifica negros e indígenas como "menos" humanos e impõe um padrão nada civilizado de violência de exploração. Esta civilização racional apoia-se na violência irracional. Por isso, Dussel afirma que o ego cogito foi precedido, na prática, pelo ego conquiro - a razão conquistadora, que submete e vence. Uma razão que explora e mata, nega a condição de humanidade de alguns para afirmar o seu ser. Uma lógica interna que, no progresso ou evolução de alguns, ocultam seu potencial genocida. A violência da colonização marca a subjetividade por uma razão que ilumina com o saber/ciência o progresso do capitalismo, ocultando nas sombras a sua barbárie que é seu contra face. Trata-se do alicerce da "superioridade" civilizacional moderna que é proposto como modelo a ser seguido. Na cultura europeia, teríamos o ápice de um processo evolutivo-progressivo que todos os humanos devem alcançar. Esse sistema de referências foi implantado globalmente não por sua força de verdade, mas pela sua capacidade de violência colonial.

O questionamento desta lógica vem, na tradição do $\mathrm{DEI}$, pelo reconhecimento da vítima como inocente, isto é, seu sacrifício não é necessário para o bem da humanidade. Afirmar a inocência da vítima é introduzir um critério ético de denúncia da injustiça. O que parece verdadeiro, trata-se de exploração. O problema central do conhecimento não está na ignorância do "bárbaro", mas na injustiça do "civilizado". Não se trata de um problema somente epistemológico, pois neste horizonte de compreensão, a morte, a exclusão e a exploração sem limites de milhares de pessoas são consideradas racionais e justas, necessárias a um futuro melhor. Quem melhor pode denunciá-lo é a própria vítima que recusa sua reificação, ser tratado como "isto". Mas, a cada vez que se acusa a injustiça da relação colonial, coloca-se em dúvida o fundamento da Modernidade ${ }^{12}$. No entanto,

\footnotetext{
${ }^{11}$ A noção de educação de Kant permite exemplificar como os modelos transcendentais oferecem parâmetros teleológicos coerentes com seus pressupostos. No caso de Kant, destacamos os pressupostos do dualismo, a visão negativa do corpo e das emoções, a humanização pelo uso da razão em sociedade, entre outros.

12 Isto permite a prática da releitura da história, presente tanto em Benjamin como na perspectiva descolonial. Dussel, por exemplo, indica Bartolomeu de Las Casas como antecedente desta denúncia, a partir de outro marco categorial. A argumentação racional de Las Casas desmonta a hipótese de um "engano" em relação a humanidade dos negros, indígenas e outros "bárbaros".
} 
somente é possível questionando princípios tacitamente aceitos, desse horizonte de compreensão que fundamenta a maneira de ser na modernidade, projetando um ser humano ilustrado e burguês, conquistador e autocentrado.

\section{DISPUTAS DE SIGNIFICADOS E APOSTAS FUNDAMENTAIS}

Paulo Freire é o teórico que expressa esta questão com clareza no clássico "Pedagogia do Oprimido" (1979). Ele não apenas organiza um conjunto de elementos de forma instigante, como ressalta a crítica a partir da perspectiva das vítimas, os oprimidos. Ele desenvolveu em sua obra uma ampla teoria educacional que explicita a relação entre pedagógica e antropológica nos fundamentos da educação. Freire compreende o processo educativo como ação que permite (ou não) ao ser humano realizar sua vocação ontológica de "ser mais". A perspectiva pedagógica de Freire insere-se numa disputa entre as possibilidades de ocorrer "vida humana" compreendidas na dialética entre humanização ou desumanização. As possibilidades da vida são decorrentes do caráter inconcluso do humano, que denota o fazer-se que é sobreposto a qualquer determinismo. A natureza humana, social e historicamente, tornou-se vocacionada a humanização. O fato de ser vocacionada e não destinada permite que exista tanto a possibilidade de realizar-se como a possibilidade de frustrar-se como tal (FREIRE, 2002, p.208).

No entanto, há concepções antropológicas vigentes e atuantes que procuram compreender as relações da vida a partir de determinismos históricos e ontológicos. Para ele é o ponto de vista da classe dominante, enquanto opressora, que deseja "transformar a mentalidade dos oprimidos e não a situação que os oprime" (FREIRE, 1979, p.78). A transformação da mentalidade visaria melhor adaptar os oprimidos à situação de opressão. Esta compreensão funda-se na concepção antropológica da "inferioridade ontológica" dos oprimidos (FREIRE, 1979, p.56), como uma diferença de humanidade, que teria sua incapacidade confirmada pela realidade histórica, com evidência empírica. Dentro desta concepção hegemônica, os oprimidos são meros "istos", inferiores por natureza, de nascença (FREIRE, 2002, p.226) e, reificados, precisam ser preparados (convencidos) no processo educacional para existir a sua vida.

Tal perspectiva indica certa disputa de significados e orientações para a vida que concedem sentido dentro de específicos horizontes de compreensão. Mesmo que o capitalismo seja um sistema que prescinde de significação para a existência aprisionando as pessoas na "jaula de aço" (Weber) sem nenhum sentido transcendental, a própria dinâmica da vida humana associada ao modo de produção e consumo de mercadorias (e de seu fetichismo), gestariam horizontes de compreensão num universo de símbolos (COELHO, 2014). Educar é sempre para um sentido da vida, para o que é capaz de realizar a pessoas humana. Se não é parte dos debates explícitos, é porque está tacitamente aceito como pressuposto. Educar significaria preparar a pessoa humana, numa sociedade complexa, a discernir entre símbolos e desejos que melhor possibilitem a significação e concretização de sua 
existência enquanto humanos. Esta é uma das teses que Jung Mo Sung defende sobre a relação entre o sistema econômico e a educação e a necessidade de um discernimento ético-político. Educa-se para que se tenha uma vida melhor e a ideia de vida melhor supõe que se responda qual é o melhor modo para o ser humano viver (SUNG, 2007). De fato, é a visão antropológica imbuída em cada proposta educacional que, delineando o sentido da vida humana (que vida é mais humana?), indica os conteúdos e métodos educacionais que são necessários para que ensine a vida mais humana.

Se as teorias educacionais estão integradas ao tempo em que se desenvolvem, a resposta ao questionamento antropológico (Que é o ser humano? Qual a melhor forma de vida para o humano?) relacionam-se com os horizontes de compreensão que dão significado para a vida nestes contextos, constituindo-se como condições necessárias para se pensar a realidade. Apontando qual é o modelo de sociedade (transcendental, perfeita), permite comparação com a realidade vigente e não só explica tal realidade, como estabelece ações para melhorá-la. O modelo de perfeição apresentado é entendido como uma ferramenta epistemológica que aponta o sentido último da ação humana pode ser a utopia da teoria de Hinkelammert. Paulo Freire indica conceito um pouco distinto quando diz que "temos também na cabeça, mais ou menos, o desenho do mundo em que gostaríamos de viver. Isto é a utopia ou o sonho que nos instiga a lutar" (FREIRE, 2002, p.240). É o que podemos chamar, acompanhando Hinkelammert (1989), de "imaginário utópico" de transformação do modo de viver. Diz Freire:

Seria horrivel se tivéssemos a sensibilidade da dor, da fome, da injustiça, da ameaça (...) se apenas sentíssemos a opressão e não pudéssemos imaginar um mundo diferente, sonhar com ele como projeto e nos entregar à luta por sua construção (FREIRE, 2002, p.239).

Se os horizontes de compreensão da vida estão referenciados no pensamento utópico, este se constitui como ferramenta epistemológica, precisam ser melhor estudados em seu papel de legitimação da ideologia vigente como um meta-sentido para toda a humanidade de forma universal (como toda ideologia, de forma naturalizada, negando seus aspectos transcendentais) ou em seu papel de gestação de alternativas como utopia ou pensamento crítico. Estas compreensões de sentido geram experiências concretas que fundam, confirmam ou modificam as apostas existenciais vitais. A educação apresenta-se como preparar possibilidades de futuro, a partir dos conflitos atuais, dentro das categorias indicadas por cada compreensão utópica. Neste sentido, o capitalismo e a Modernidade oferecem categorias para a compreensão do que seria a vida boa para qualquer pessoa humana, uma vida que se realiza na relação com as mercadorias, a partir de modelos de consumo.

Paulo Freire afirma que a absolutização da desumanização como ontológica incapacidade dos oprimidos transforma a utopia vigente em mito. Este mito gera uma fé que oprime e legitima a prática da opressão. Seria uma aposta fundamental no "ter mais" como contradição a fé no "ser mais" como realização humana. Atraídos e referenciados pela noção do que é ter uma vida boa, existe um conjunto de possibilidades e a educação deve ajudar na escolha dos critérios para optar entre as existentes. Vale ressaltar que, para Paulo Freire, não é a escola que ensina um modelo como o hegemônico opressor como correto. É a contradição real da vida que demonstra claramente a todos quem vence e vive melhor, sem escrúpulos ou modéstia. A escola reforça, justifica, legitima com "ar" de ciência, a 
ciência moderna, supostamente neutra, os horizontes de compreensão que se constituem expressão da visão social de mundo.

\section{CONTRIBUIÇÕES PARA DEBATE}

O combate pela significação da vida humana revela a formulação de atitudes básicas de sentido último que apresenta incompatibilidade com diversidades, isto é, um sentido último, uma visão básica de mundo para ser última, supõe estar acima de outras formulações de valores. Por isto são inconciliáveis dois modelos diferentes e é necessária a escolha decisiva (uma "aposta"). Se, por um lado, há um sentido último e necessário e, por outro lado, a razão instrumental, por seus limites, não discerne sobre os sentidos que disputam a significação última, precisamos perguntar que tipo de racionalidade é capaz de refletir sobre tal questão. A questão é que se sempre haveria, em cada época, um meta-sentido/ apostas fundamentais que mantém afinidade eletiva com o espírito que motiva tal época, como um ethos. Tal aposta seria integrada e partícipe deste espírito. Compõe o âmbito da legitimidade da vida sob o capitalismo, no qual se elaboram os projetos de vida e formação do humano. As pedagogias hegemônicas se integram plenamente a Modernidade, derivando seus princípios dos filósofos estratégicos da cultura burguesa. Ao mesmo tempo, negam valor e plausibilidade à práticas pedagógicas alternativas, ocultando perspectivas divergentes.

O ethos de nossa época, que se expressa em um "espírito do capitalismo"13, referencia-se em um núcleo ético-mítico que, ocultado, legitima seus pressupostos. Segundo Dussel, somente na Modernidade, que se entende como radicalmente secular, desencantada, neutra e referenciada exclusivamente na razão instrumental, o sentido parece reduzir-se, tornar-se difuso ou difícil de discernir (mas nunca ausente). Para ele:

\footnotetext{
Todo sistema de civilização se organiza em torno a (...) um núcleo ético mítico, os valores fundamentais do grupo (...). São os níveis mais profundos de uma civilização: aquelas estruturas, fins ou valores que não são nem vistos como objetivo, nem criticados, e que, no entanto, são os objetivos para os quais tendem todas as condutas, são os valores que justificam a eleição e utilização dos instrumentos. (DUSSEL, 1970, p.11).
}

Existiria algo que fundamenta as escolhas de instrumentais dentro de cada paradigma. Este algo permanece oculto, não discutido, como pressuposto inquestionável, real por si e por isto mesmo válido. Este algo que Dussel denomina "núcleo ético-mítico" seria aquilo que combina coerentemente os elementos que constituem paradigma, marcos categoriais a partir dos quais se elaboram os pensamentos sociais. Em Franz Hinkelammert, o tema do núcleo ético-mítico é apresentado como um marco categorial, que é constituído pela realidade, mas através do qual essa mesma realidade se explica. Constitui o limite do horizonte de compreensão de uma época e dificilmente é refutado, pois

\footnotetext{
${ }^{13}$ Sobre o tema, veja: BENSAÏD, 2000.
} 
apresenta como fato empírico e credível somente o que está de acordo com seus pressupostos. A crítica da realidade como um todo, supõe compreender e criticar seu marco categorial.

O marco categorial da sociedade burguesa é o mesmo da sociedade moderna, que mais uma vez se totaliza na estratégia da globalização (HINKELAMMERT, 2014, p.213). Nesse marco categorial, inclui a ideia de progresso contínuo, de crescimento infinito, de eficiência perfeita, mas também a do sacrifício necessário. No entanto, para Hinkelammert, em acordo com a definição de Dussel, marcos categoriais não são explicados pela pura razão instrumental, pois eles se constituem de paradigmas que articulam a razão mítica e a razão utópica, e supõe a dimensão mítico-teológica. Assim, o desafio está no fato de que "não se pode contestar a este marco categorial e a esta razão mítica sem desenvolver outro marco categorial a partir da afirmação de que o sentido da vida é vivê-la e vivê-la entre todos" (HINKELAMMERT, 2014, p.219).

Entender a crítica da razão mítica e da razão utópica podem colaborar em novas abordagens da Filosofia da Educação em compreender o marco categorial sob o qual o ethos capitalista moderno se referencia de forma não discutida, mas presente, como estrutura impensável que the serve de pressuposto. A relação das propostas educacionais e as apostas fundamentais merece ser melhor aprofundada. Seria possível pensar, conspirar, educar para apostas em projetos fora do sistema e dos horizontes de plausibilidade estabelecidos como válidos? Dussel propõe a categoria da exterioridade para desafiar as possibilidades de resposta. Se o sistema se absolutiza econômica, epistêmica e socialmente, apresentando-se como uma totalidade, a exterioridade refere-se ao lugar do outro, do pobre, do que não sabe, do que não é, isto é, aquele que foi considerado na condição de "nada" frente o sistema. A racionalidade dominante indica o verdadeiro e acusa o falso, sempre referenciado em si mesmo, em sua totalidade, condenando o que está fora como problema, não existente ou relevante, como perigoso.

$\mathrm{Na}$ exterioridade, então, temos o conjunto de vítimas, daqueles que são negados de alguma forma. A vítima pode ser entendida como o explorado, que de dentro do sistema, pelo seu funcionamento normal, sofrem a opressão de sua lógica de produção. Pode ser também algum afetado, daqueles que sofrem pela hegemonia imposta, que de dentro do sistema, são considerados fora do modelo de ser humano recomendável. Ainda, podem ser as vítimas excluídas, que de diversas maneiras são colocadas para "fora do sistema", tratadas como inexistente, irrelevante ou desnecessário (DUSSEL, 2000). Por vezes, a condição da exterioridade permite conhecer mais profundamente o sistema iluminado nas suas sombras. São aqueles que sofrem o horror que este projeto de civilização e de humanidade impõe a tanta gente, experimentando o navio negreiro, a escravidão, os campos de concentração, a trincheira das guerras, a jornada de trabalho exaustiva, a fome e negação de direitos, os campos de refugiados, a sobrevivência nas ruas frias das cidades, o calor sob a lona dos acampamentos, a subcidadania de tantos, entre outros.

O sistema totalizado estabelece sua "ontologia", dentro do qual estão seus parâmetros de razoabilidade e seu horizonte de plausibilidades. O que acontece "além" deste horizonte, "que não tem sentido para o sistema" (DUSSEL, 1994, p.67), indica a transcendência. Esta transcendência interpela 
o horizonte ontológico. Hinkelammert chamou esta relação de "transcendentalidade no interior da vida real e concreta" (HINKELAMMERT, 1983), na qual as ausências específicas do sistema, gestam uma realidade diferente. Quem sabe este conceito não está expresso na humanidade negada ao sujeito que se vocaciona a "ser mais". A realidade negada, no interior da vida real, permite pensar a transcendência do horizonte de sentidos do sistema que se considera limite do razoável.

É por isso que Lauri Wirth indica como tarefa da crítica a "construção de novos horizontes de plausibilidades, a partir das alteridades subsumidas e ocultadas pelo lento e longo processo de consolidação do sistema mundial que hoje vivemos" (WIRTH, 2013, p.139). Trata-se do nível da apropriação simbólica, que modifica critérios de significação juntamente com as visões de projetos a construir, na práxis de sujeitização da vítima. Permanece a necessidade de aprofundar quais seriam as condições para reconhecer a vítima como alguém e, na contramão do sistema, defender a sua inocência e o valor de sua vida como critério.

Rieger, Míguez e Sung (2012) analisam o uso da transcendência (oculta) do sistema capitalista como instrumento de dominação, em outros dois elementos articulados, além da imposição de um horizonte de plausibilidade: através das seguintes funções: a consolidação de um modelo de desejo, que pelo fascínio e gera adesão sobre a forma como se vive e a elaboração de uma consciência de justificação, em que mesmo ações evidentemente más (morte, por exemplo), podem ser compreendidas em um horizonte de sentido no qual parecem geradoras de um bem maior e/ou futuro (ética) enquanto projetos de sociedade (política). Propostas educacionais teriam o potencial para gestar horizontes de plausibilidade alternativos, inspirados pela crítica deste setor, do capitalismo como religião, articulando estes três aspectos: os horizontes de compreensão, os modelos de humanidade e as teodiceias de legitimação ${ }^{14}$.

Vale pensar também que, uma Filosofia da Educação que pretende avançar nos debates descoloniais, precisa debater em conjunto com os demais especialistas da educação as consequências para questões como a subversão da noção de história, que além de eurocentrada e ocidental, centrase no pressuposto da evolução na social e individual. A questão do que é ciência e o saber válido, bem como das estruturas do que é possível pensar, também são desafios centrais para as concepções de educação para evitar a exclusividade de uma ciência burguesa sem cair na negação do pensamento racional. Que tipo de racionalidade permite entender a presença da razão mítica e da razão utópica na construção de sentidos para a vida, seja na formação da subjetividade humana ou na estrutura do modo de produção? Questionar o marco categorial do saber com luz que ilumina, transmitido por outros para uma mudança ontológica modificaria de que forma as propostas educativas? Olhando a partir dos vencidos da história, é possível negar a legitimidade do marco categorial do sacrifício necessário, retirando seus pressupostos da expectativa de formação humana?

\footnotetext{
${ }^{14}$ Há um argumento de fundo que não explicitamos neste texto pelos seus limites: parece-nos que em Pedagogia do Oprimido, Paulo Freire resvala ou debate a maior parte destes temas, do seu jeito.
} 


\section{CONCLUSÃO}

O mundo moderno, iluminado e racional, conheceu as maiores hecatombes em humanidade. As guerras mundiais e os campos de concentração explicitam a violência no coração da "civilização". Desde a perspectiva das vítimas, podemos dizer que já tínhamos visto este grau de desumanização, na exploração da África ou da América. Parece que não se aprendeu muito com a lição, basta olhar os novos campos de concentração, o encarceramento em massa, conflitos e assassinatos, além da condição de subvida, agora não só nas periferias, mas espalhados pela globalidade do mundo. A globalização radicaliza este padrão, em uma convergência de crises (econômica, social e ambiental) que coloca a vida de toda a humanidade em perigo. É urgente questionar os pressupostos de uma racionalidade que fundamenta uma civilização que mata e caminha ao suicídio.

Discutir os horizontes de plausibilidade e modelos de humanidade não corre o risco de um essencialismo filosófico, como uma questão de preferências epistêmicas, se mantivermos com locus enunciationes a vítima, na materialidade concreta de seu sofrimento social. Desse locus, não se entende a epistemologia e o problema do conhecimento (e sua transmissão) como isolados do contexto da vida real. É um local de produção intelectual que no território sua metáfora, não como espaço geográfico, mas como opção geopolítica. Não está no âmbito dos discursos a serem desconstruídos ou identidades a serem resgatadas, mas de certa práxis que vai aos poucos tateando sua descolonização, quando necessário para sua libertação.

Descolonizar a subjetividade e modificar as condições reais da vida humana exigem enfrentar a estrutura fundamental de credibilidade do capitalismo em sua versão neoliberal. Uma educação para des-fascinar a vida do brilho frágil das mercadorias. Uma educação que contribua para des-fetichizar a existência, que não compreenda o papel de educar como integrar ao horizonte de plausibilidade vigente, mas como possibilitar a vida. Que esteja em sintonia com as novas lutas por emancipação e pela sobrevivência humana. 


\section{REFERÊNCIAS}

1. ASCHCROFT, B. et.al. The post-colonial studies reader. London/New York: Routledge, 1995.

2. ANZALDÚA, G. La consciência de la mestiza. Estudos Feministas. Florianópolis, set-dez/2005, p. 704-719.

3. BENJAMIN, W. Capitalismo como Religião. São Paulo: Boitempo, 2013.

4. BENSAïD, D. Le sourire du Spectre. Paris: Michalon, 2000.

5. CASTRO-GÓMEZ, S.; RESTREPO, E. Genealogías de la colombianidad. Bogotá: Pontificia Universidad Javeriana, 2008.

6. COELHO, A. S. Capitalismo como religião: uma crítica a seus fundamentos mítico-teológicos. 2014. 281p. Tese (Doutorado em Ciências da Religião) - UMESP, São Bernardo do Campo.

7. DUSSEL, E. América Latina y consciência cristiana. Quito: Ed. D.Bosco, 1970. 1492 o encobrimento do outro. Petrópolis: Vozes, 1993. Ética comunitária. 3 ed., Petrópolis: Vozes, 1994. Ética da Libertação. Petrópolis: Vozes, 2000. Europa, modernidade e eurocentrismo. In.: LANDER, E. (org). A colonialidade do saber. Buenos Aires: CLACSO, 2005, p.55-70. Política da libertação: história mundial e crítica. Passo Fundo: IFIBE, 2014.

13. FREIRE, Paulo. Pedagogia do oprimido. Rio de Janeiro: Paz e Terra, 1979. Cartas a Cristina. 2. ed. São Paulo: Ed. UNESP, 2002.

GROSFOGUEL, R. Para descolonizar os estudos de economia política e os estudos póscoloniais. Revista Crítica de Ciências Sociais, Coimbra, n. 80, p. 115-147, mar. 2008. 
18. genocidio económico-social in. CORAGGIO et al., Reinventar la izquierda en el siglo XXI. Los Polvorines: UNGS, 2014, p. 207-221.

21. HINKELAMMERT, F; ASSMANN, H. A idolatria do mercado. Petrópolis: Vozes, 1989. 2002, p.04-28.

28. RICHARD, P. et al. A luta dos deuses. São Paulo: Paulinas, 1982.

29. SUNG, J. M. Educar para reencantar a vida. Petrópolis: Vozes, $2^{\mathrm{a}}$ ed., 2007.

30. O que é Cristianismo de Libertação. São Paulo: Perseu Abramo, 2016.

MALDONADO-TORRES, N. Sobre la colonialidad del ser, in. CASTRO-GÓMEZ, S.; GROSFOGUEL, R. (ed.). El Giro Decolonial. Bogotá: lesco, 2007, p.127-167.

MÉSZÁROS, I. A Educação para além do capital. São Paulo: Boitempo, 2005.

QUIJANO, A. Colonialidade, poder, globalização e democracia. Novos Rumos, v. 4, ano 17, n.37, Cristianismo de Libertação. São Paulo: Paulus, 2008.

SUNG, J. M.; MÍGUEZ, N.; RIEGER, J. Para além do espírito do Império. S.Paulo: Paulinas, 2012. WALSH, C. Interculturalidad, Estado, Sociedad. Quito: Ed. Abya-Yala, 2009.

WIRTH, L. Religião e epistemologias pós-coloniais, in: PASSOS, J.D.; USARKI, F. Compêndio de Ciências da Religião. São Paulo: Paulinas - Paulus, 2013, p.129-142. 


\section{Allan da Silva Coelho}

Licenciado em Filosofia, Doutor em Ciências da Religião, professor no PPGE da Universidade Metodista de Piracicaba-UNIMEP.

\section{Como citar este documento:}

COELHO, Allan da Silva. Horizontes de plausibilidade sob a crítica da filosofia: entre luzes, horrores e vítimas. Reflexão e Ação, Santa Cruz do Sul, v. 26, n. 3, nov. 2018. ISSN 1982-9949. Disponível em: $<$ https://online.unisc.br/seer/index.php/reflex/article/view/12470>. Acesso em: 19 nov. 2018. doi:https://doi.org/10.17058/rea.v26i3.12470. 